\title{
Argumentacãa e Leitura no Gênero Carta do Leitor
}

\author{
Argumentation and Reading in Reader's Letter
}

\section{Isabel Cristina CORDEIRO*}

Resumo: Este artigo trata dos recursos persuasivos da Semântica Argumentativa e da Linguística Textual, aliados às estratégias cognitivas da Teoria da Leitura, revelando a relação de complementaridade que se instaura nesses campos de estudo para a formação de leitores mais críticos. O corpus selecionado para análise é uma Carta do Leitor, gênero textual altamente argumentativo e produto de interação social. Nossa proposta relaciona alguns recursos como os operadores argumentativos, os modalizadores, a adjetivação e a intertextualidade aos aspectos cognitivos de leitura como o conhecimento prévio - imprescindível à compreensão da intertextualidade, entre outras estratégias de processamento cognitivo-textual que representam o conhecimento que os leitores possuem sobre compreensão de discursos. $\mathrm{O}$ objetivo é direcionar o leitor a identificar, de maneira mais dinâmica e produtiva, os aspectos discursivos que permeiam a leitura para, desde o primeiro contato com o texto, ser capaz de estabelecer suas metas e intencionalidades, tendo como fundamento a parceria entre argumentação e leitura. Assim, esperamos levar o leitor a uma reflexão mais crítica daquilo que lê, contemplando uma teoria sociointeracionista com ênfase nas habilidades cognitivas de cada indivíduo.

Palavras-chave: Argumentação. Leitura. Carta do leitor.

Abstract: The objective of this work is to study the persuasive resources present in Argumentative Semantics and Textual Linguistics together with cognitive strategies of the Theory of Reading which reveals the complementary relationship that is present in these field of study in the

\footnotetext{
* Doutorado em Estudos da Linguagem na Universidade Estadual de Londrina (2007). Docente do Departamento de Letras Vernáculas e Clássicas da UEL. Contato: isabel-cordeiro@uol.com.br
} 
formation of critical readers. The subject selected is the analysis of the reader's letter, a highly argumentative textual genre and the product of a social interaction. Our purpose links some resources such as argumentative operators, modal adverbs, adjective, intertextuality, reading cognitive aspects of previous necessary knowledge to intertextuality comprehension schemes, among other strategies of cognitive textual processing that represent the knowledge that readers have about the comprehension of discourses. The objective is to lead the reader to identify in the most dynamic and productive way, the discursive aspects that permeate the reading from the first contact with the text, to be able to establish goals and intentions, have a partnership between argumentation and reading as a foundation. In this manner, we hope to lead the reader to a more critical reflection of the material he reads contemplating a social interactionist theory with and emphasis on the cognitive abilities of each individual.

Key-words: Argumentation. Reading. Reader's letter.

\section{Introdução}

A construção de sentidos de um texto deve considerar o modo de organização e funcionamento do discurso, as modalidades que uma palavra assume - uma mesma palavra pode funcionar, objetivamente ou subjetivamente, segundo as intenções do produtor - e, ainda, as estratégias de interlocução social e histórica dos sujeitos envolvidos no ato de comunicação. A Carta do Leitor caracteriza-se pela ausência de contato imediato entre destinador e destinatário, atendendo a várias intenções comunicativas. No processo de desenvolvimento do discurso, há um jogo de manipulação que parte do enunciador e se reflete no enunciatário (leitor), porque o texto é um lugar de manipulação consciente, em que o homem organiza, da melhor maneira possível, os elementos de expressão disponíveis na língua para veicular seu discurso. Analisaremos a Carta do Leitor, a seguir, da Revista Veja de 6 de janeiro de 2007, que apresenta recursos linguístico-argumentativos que marcam a interveniência de uma avaliação persuasiva do falante. 
1 Se os gastos de um ano da Nasa, da agência espacial européia, da japonesa e de outras fossem aplicados na preservação do planeta, o 3 efeito estufa com certeza não seria a ameaça que é hoje. Não que a pesquisa espacial não seja importante e interessante, na verdade 5 muito mais interessante do que importante, mas é uma questão de prioridade. Os melhores cérebros e uma astronômica cifra são 7 aplicados em incertezas, enquanto nossa única certeza desmorona.

Wagner Lisso

Valinhos, SP

Dentre as principais estratégias para efetivar a interação entre texto e leitor, o título da Carta - Aquecimento Global - é o primeiro a influenciar o leitor com a utilização de termos que resgatam não só o assunto tratado como também o contexto de produção da Carta.

Vivemos um momento em que a preservação de nosso planeta, bem como sua rica biodiversidade, é um dos maiores desafios da espécie humana. Assim, a situacionalidade revela-se no fato de que a não conscientização da Humanidade acerca do "megaproblema ambiental" pode agravar o efeito estufa e ameaçar a harmonia do planeta.

Nesse sentido, a construção da Carta emite um julgamento a respeito do Aquecimento Global. O produtor (Wagner Lisso) sugere soluções com suas estratégias discursivas e participa da construção da imagem que o leitor produz sobre a preservação do planeta e o efeito estufa. Essa interação (produtor-leitor) contribui para edificar os sentidos e criar um contrato de comunicação entre os interlocutores. Dessa forma, a linguagem utilizada pressupõe a existência de um gênero (Carta do Leitor) com um contrato de fala que estabeleça a autenticidade e a seriedade do texto e de um público-alvo a quem esse discurso seja destinado, estabelecendo, assim, as estratégias interacionais.

Koch e Travaglia (2002, p. 76) consideram a situacionalidade condição da coerência: “[...] textos ditos incoerentes eram perfeitamente coerentes, e faziam sentido, desde que os imaginássemos numa situação X, com determinadas características".

Percebemos, então, que o contexto é dinâmico e o leitor (re)constrói os traços relevantes desse contexto para alcançar sentidos na leitura. Dessa 
forma, o produtor da Carta reconstrói o contexto apresentado no texto-fonte "7 megassoluções para um megaproblema" (Veja, 30/12/2006), acrescentando ao texto seu conhecimento sobre a atual situação ambiental do planeta.

O conhecimento prévio é importante para o processo de compreensão do texto, por isso produtor e leitor devem ter conhecimentos com grau de similaridade, ou seja, é o conhecimento partilhado que determina a carga informacional do texto: o dado e o novo. O produtor da Carta apresenta informações (dado) retiradas do texto-fonte e, também, sugere soluções (novo), partilhando com o interlocutor suas crenças e opiniões.

A intertextualidade implícita promove, no leitor, certa curiosidade em conhecer os 7 projetos radicais para salvar o planeta, isto é, as "7 megassoluções para o megaproblema ambiental", e o entendimento da Carta depende do intertexto, assim como o intertexto é fator de coerência nesse discurso. As 7 megassoluções propostas no texto-fonte são:

- Trocar o carvão pelo átomo;

- Enterrar os gases tóxicos;

- Colocar refletores de calor em órbita;

- Pôr um guarda-sol no espaço;

- Espalhar enxofre na atmosfera;

- Multiplicar o fitoplâncton;

- Colocar mais água nas nuvens.

A Carta do Leitor é um exemplo de que o produtor pressupõe a participação do leitor na construção dos sentidos, considerando que os conhecimentos anteriores de cada um não são iguais, mas interagem dinamicamente, conforme explicam Koch e Elias (2006).

A argumentação, conforme exposto, possui um repertório de elementos linguísticos utilizados pelo enunciador com a finalidade de persuadir o seu interlocutor, dentre eles, os operadores argumentativos.

\section{A) Operadores Argumentativos}

Considerando a argumentatividade da linguagem, podemos afirmar que não existe discurso neutro e que as condições argumentativas dependem do enunciatário, pois subjacente a todo discurso está o fato de se pretender 
uma compreensão por parte do interlocutor e é em torno dele que se utilizam diversos procedimentos argumentativos.

A finalidade última de todo ato de comunicação não é informar, mas é persuadir o outro a aceitar o que está sendo comunicado.[...] A linguagem é sempre comunicação (e, portanto, persuasão), mas ela o é na medida em que é produção de sentido. (FIORIN, 1989, p. 52).

$\mathrm{Na}$ linha 1, o produtor inicia o discurso com o operador argumentativo $\mathbf{S E}$, estabelecendo uma relação lógico-semântica de condicionalidade:

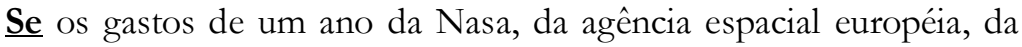
japonesa e de outras fossem aplicados na preservação do planeta, o efeito estufa com certeza não seria a ameaça que é hoje.

Para tanto, utiliza-se da seguinte construção:

\section{\begin{tabular}{|l|l|l}
\hline SE ORAÇÃO CONDICIONAL & ORAÇÃO PRINCIPAL \\
\hline
\end{tabular}}

Assim, temos:

Se os gastos de um ano da Nasa, da agência espacial européia, da japonesa e de outras fossem aplicados na preservação do planeta,

o efeito estufa com certeza não seria a ameaça que é hoje.

O produtor inicia a Carta com uma oração condicional (hipotética/ incerta/eventual/possível), que contém a informação principal, direcionando o leitor a questionar "os gastos com a pesquisa espacial":

SE NÃO investir um ano em pesquisa espacial. $\longrightarrow$ Arg. 1

O efeito estufa NÃO será ameaça. $\longrightarrow$ Arg. 2 
Isso significa que:

SE investir em pesquisa espacial. $\longrightarrow$ O efeito estufa será uma ameaça.

As orações condicionais, conforme dito anteriormente, reforçam os sentidos pretendidos pela oração principal. Ademais, a noção de condicionalidade gerada pelo operador SE (hipótese) cria uma relação paradoxal frente ao modalizador com certeza (certamente), presente na oração principal:

[...] o efeito estufa com certeza não seria a ameaça que é hoje.

Assim:

a) Gastar com pesquisa espacial acarreta em $\mathbf{X}$.

b) Gastar com a preservação do planeta acarreta em $\mathbf{Y}$.

Ou seja:

c) $\mathbf{S E}$ investir um ano em pesquisa espacial = AMEAÇA AMBIENTAL

d) $\mathbf{S E}$ investir um ano na preservação do planeta = NÃO AMEAÇA AMBIENTAL

Ou ainda:

e) $\mathbf{S E}$ investir um ano em pesquisa espacial.

$\longrightarrow$ COM CERTEZA ameaça ambiental.

Mas:

f) SE investir na preservação do planeta. COM CERTEZA não ameaça ambiental.

Vejamos as principais acepções dos termos conjunção e condicional: 


\section{Conjunção}

[Do lat. conjunctione] [...]

- Conjunção condicional

E. ling.

1. conjunção subordinativa que inicia uma oração subordinada em que se expressa uma hipótese ou condição necessária para que se realize ou não a ação principal: se, caso, contanto que, salvo se, dado que, etc.

$[\ldots]$

\section{Condicional}

[Do lat. conditionale]

Adj.

1. Dependente de condição.

$[\ldots]$

4. E. ling. Que indica ser a verdade de uma proposição dependente da verdade de outra.

s.f. $[\ldots]$

9. E. ling. Conjunção condicional.

Segundo a acepção 4, a verdade da oração condicional depende da verdade da oração principal, ou seja:

\section{VERDADE 1}

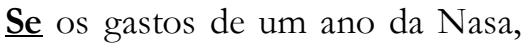
da agência espacial européia, da japonesa e de outras fossem aplicados na preservação do planeta,
VERDADE 2

o efeito estufa com certeza não seria a ameaça que é hoje.

Esse jogo argumentativo leva o leitor a questionar SE, de fato, um ano de investimento seria suficiente para uma não ameaça ambiental, revelando a interação que se instaura na leitura da Carta do Leitor.

Os operadores argumentativos que indicam comparação estabelecem entre um termo comparante e um termo comparado, uma relação de inferioridade, superioridade ou igualdade, objetivando a uma dada conclusão.

$\mathrm{Na}$ linha 5, o uso do comparativo de superioridade mais...do que orienta o leitor para uma conclusão favorável ao ponto de vista do produtor: 
Não que a pesquisa espacial não seja importante e interessante, na verdade muito mais interessante do que importante, mas é uma questão de prioridade.

Koch (2002a) ressalta que os operadores argumentativos, ao introduzirem um enunciado, determinam-lhe a orientação argumentativa, pois as relações que estabelecem podem ser pragmáticas, argumentativas, retóricas ou ideológicas. Para a referida autora, são relações do tipo discursivo

responsáveis pela estruturação de enunciados em textos, por meio de encadeamentos sucessivos de enunciados, cada um dos quais resultante de um ato de linguagem particular. Esse encadeamento é feito, geralmente, por meio dos operadores argumentativos (ou operadores do discurso). (KOCH, 2002a, p. 130).

Na comparação, há confronto de duas realidades diferentes, revelando um paralelo entre dois significados:

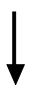

MAIS $\underline{\text { interessante }}$
DO QUE importante

Há, também, outros recursos presentes na construção desse enunciado que traduzem a intenção argumentativa do enunciador, revelando uma subjetividade "marcada" no ato da comparação: o modalizador na verdade (indica certeza); o intensificador muito (mais) reforça o adjetivo interessante e minimiza o adjetivo importante; o jogo de palavras (alteração da ordem dos adjetivos importante e interessante); e o operador argumentativo mas (contrapõe argumentos). 


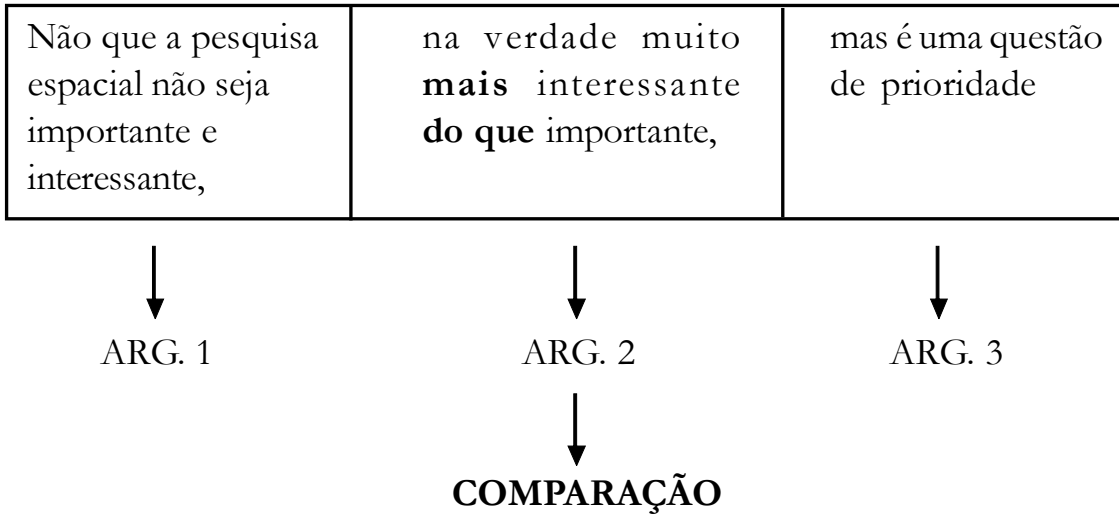

Notamos que o argumento 2 (a comparação) (re)produz uma opinião do produtor da Carta. Assim, esse enunciado comparativo, como operador argumentativo, denuncia uma atitude do locutor diante do seu ato de fala.

Na linha 5, temos o operador de oposição MAS:

Não que a pesquisa espacial não seja importante e interessante, na verdade muito mais interessante do que importante, mas é uma questão de prioridade.

Segundo Koch (2002a, p. 229), o MAS “opõe dois atos ilocucionários: concordância (explícito) X discordância (subentendido)”.

Não que a pesquisa espacial não seja importante e interessante, na verdade muito mais interessante

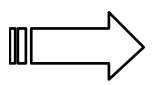
Arg. 1 (concordância) do que importante,

\section{$\mathrm{X}$}

MAS (discordância)

é uma questão de prioridade.

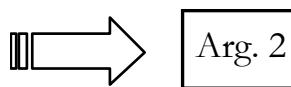


O leitor infere que, mesmo interessante e importante, a pesquisa espacial não é prioridade e sim a pesquisa ambiental. O operador MAS contrapõe argumentos enunciados de perspectivas diferentes, orienta o leitor para conclusões opostas, contrárias, devendo prevalecer a orientação do enunciado introduzido por ele.

Assim, temos:
a) PESQUISA ESPACIAL $\mathrm{X}$
QUESTÃO AMBIENTAL
b) INTERESSANTE
$\mathrm{X}$ IMPORTANTE
c) NÃO PRIORIDADE $\mathrm{X}$
PRIORIDADE

\section{MAS}

Ou seja:

A pesquisa espacial

acontece. (não prioridade)

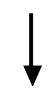

ARG. 1

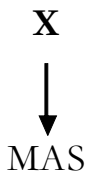

A questão ambiental

é prioridade.

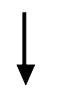

ARG. 2

O produtor da Carta utiliza o operador MAS para questionar a prioridade das pesquisas (espacial $\mathrm{x}$ ambiental) e introduz um argumento que leva o interlocutor a concluir que investir na pesquisa ambiental é, de fato, uma prioridade. Afinal, "o texto é uma unidade. E sua unidade é um efeito ideológico da posição do autor” (GUIMARÃES, 1987, p. 14).

$\mathrm{Na}$ linha 7, encontramos o operador enquanto, expressando simultaneidade temporal:

Os melhores cérebros e uma astronômica cifra são aplicados em incertezas, enquanto nossa (conj.) 1. No tempo em que.

2. Ao passo que.

(...) única certeza desmorona. 
Para Koch (2002a), o operador enquanto é "marcador de confronto" e, nesse contexto, significa ao passo que, marcando a noção de simultaneidade.

Os melhores cérebros e uma astronômica cifra são aplicados em incertezas,

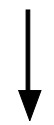

ARG. 1

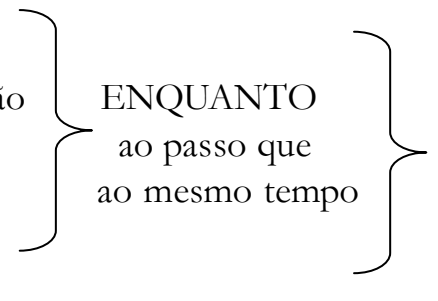

Portanto, há um confronto entre: nossa única certeza desmorona

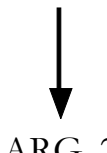

ARG. 2

INCERTEZA (pesquisa espacial) X CERTEZA (nosso Planeta)

Como salienta Guimarães (1987, p. 195), “a orientação argumentativa é o modo de organização do texto", ou seja, o modo de construção da progressão textual de forma que, no texto, o discurso representa as intenções do locutor.

\section{B) Advérbios Modalizadores}

Considerando-se os modalizadores como atos ilocucionários, dotados de valor argumentativo, já que revelam a atitude do falante perante o enunciado que produz, Koch (2002a) classifica o modalizador com certeza (= certamente) como epistêmico. Para ela (2002a, p. 84), "no eixo epistêmico, revela-se a atitude de conhecimento do locutor, sua manifestação de crença em relação ao conteúdo veiculado".

Vejamos o modalizador na linha 3:

Se os gastos de um ano da Nasa, da agência espacial européia, da japonesa e de outras fossem aplicados na preservação do planeta, o efeito estufa com certeza não seria a ameaça que é hoje.

O uso do modalizador objetivo com certeza (certamente) manifesta a condição de verdade imposta ao enunciado, na perspectiva do produtor 
(o efeito estufa não ser uma ameaça), e revela o grau de certeza do locutor em relação aos fatos enunciados.

Neves (2000, p. 245) salienta que os advérbios modalizadores epistêmicos asseveram, marcam uma adesão do falante ao que ele diz, "indicam uma crença, uma opinião, uma expectativa sobre a asserção" e avaliam "o valor de verdade do que é dito no enunciado".

É o que ocorre, também, na linha 4, com o modalizador objetivo na verdade (verdadeiramente):

Não que a pesquisa espacial não seja importante e interessante, na verdade muito mais interessante do que importante, mas é uma questão de prioridade.

Neves classifica o modalizador na verdade como "modalizador epistêmico asseverativo afirmativo" (de factualidade - é certo que) e conclui: "O conteúdo do que se afirma ou do que se nega é apresentado pelo falante como um fato, como fora de dúvida, o que é reforçado pelo advérbio".

Dentre as diferentes acepções, ligadas ao saber do falante, que os advérbios podem ter, a autora analisa esse modalizador com a seguinte acepção:

- Verdade dos fatos: verdadeiramente (na verdade), realmente, na realidade.

Por meio do modalizador, o produtor expressa sua opinião a respeito da pesquisa espacial: "verdadeiramente mais interessante do que importante", buscando a adesão do interlocutor para o conteúdo do enunciado seguinte: a questão da prioridade na preservação do planeta.

\section{C) Adjetivação}

Monteiro (1991), ao comentar os valores do adjetivo, afirma que ele forma com o substantivo uma unidade indissolúvel,

... é semanticamente definido como a palavra que exprime noções qualitativas dos seres. [...] É uma das classes que mais indicam o lado afetivo da comunicação. (MONTEIRO, 1991, p. 62). 
Embora manifeste uma atitude valorativa, existem adjetivos mais objetivos - com carga menos intensa de afetividade - como a oração adjetiva presente na linha 3:

Se os gastos de um ano da Nasa, da agência espacial européia, da japonesa e de outras fossem aplicados na preservação do planeta, o efeito estufa com certeza não seria a ameaça que é hoje.

A oração subordinada adjetiva exerce função sintática própria do adjetivo em relação ao termo da oração principal. "Os pronomes relativos introduzem uma oração de função adnominal, isto é, uma oração adjetiva”. (NEVES, 2000, p. 365).

a) [...] o efeito estufa com certeza não seria a ameaça que é hoje.

\section{Oração adjetiva}

O pronome relativo QUE é anafórico, refere-se ao antecedente ameaça:

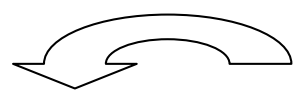

b) ... o efeito estufa com certeza não seria a ameaça

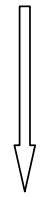

ORAÇÃO PRINCIPAL

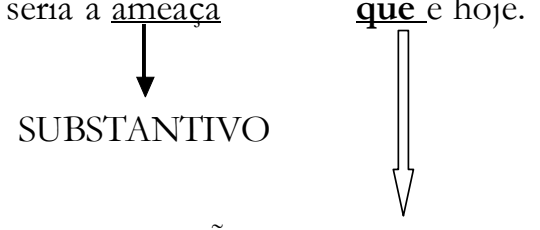

ORAÇÃO SUBORDINADA ADJETIVA RESTRITIVA

c) ameaça que

Oração adjetiva
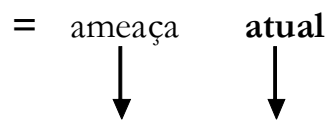

substantivo adjetivo (adjunto adnominal)

Assim, a oração adjetiva posposta ao substantivo (ameaça) atribui carga maior de objetividade ao efeito da adjetivação. Neves (2000, p. 377) acrescenta que as "as construções que contêm uma oração adjetiva restritiva 
envolvem uma pressuposição”. Essa pressuposição pode ser factual ou hipotética.

Vejamos os enunciados:

1) O efeito estufa é uma ameaça atual.

2) Se aplicassem recursos na preservação do planeta, o efeito estufa não seria a ameaça que é hoje.

Os enunciados 1 e 2 pressupõem:

3) O efeito estufa é uma ameaça atual e não antiga.

4) Investir na preservação do planeta é prioridade; logo, a pesquisa espacial não é prioridade.

Nas orientações de Neves (2000, p. 204), com os adjetivos colocados após os substantivos, "a qualificação diria respeito mais evidentemente a propriedades intensionais entendidas como objetivamente indicadas, configurando-se um uso mais descritivo".

Os adjetivos qualificadores presentes nas linhas 4 e 5 revelam que a mudança de ordem dos próprios adjetivos - mais objetivos ou mais subjetivos - gera diferenças nos resultados semânticos. Vejamos:

Não que a pesquisa espacial não seja importante e interessante, na verdade muito mais interessante do que importante, mas é uma questão de prioridade.

\begin{tabular}{|l|}
\hline \multicolumn{1}{|c|}{ Importante } \\
[Do lat. importante; part. Pres. de \\
importare.] \\
Adj. \\
1.Que tem importância, mérito; \\
meritório,essencial. \\
2.Que merece consideração, apreço. \\
3.Que importa, necessário, \\
interessante. \\
{$[\ldots]$}
\end{tabular}

\begin{tabular}{|l|}
\hline \multicolumn{1}{|c|}{ Interessante } \\
[De interessar + -nte.] \\
1.Que interessa; importante \\
2.Que prende a atenção, a \\
curiosidade, ou cativa o \\
espírito. \\
3.Atraente, simpático. \\
4.Estranho, curioso. \\
[...] \\
\hline
\end{tabular}


No $1^{\circ}$ caso, a adjetivação posposta importante e interessante expressa a opinião do produtor com carga menos intensa de afetividade. Já no $2^{\circ}$ caso, (muito mais) interessante (do que) importante, a carga emotiva é mais intensa, há comprometimento maior do produtor com o que ele diz e, ainda, a presença do intensificador muito (mais) e do operador de comparação de superioridade (mais...do que) reforçam a opinião do produtor da Carta. Nesse sentido, a escolha lexical e o jogo com os adjetivos interferem nos sentidos pretendidos pelo enunciador, pois esse jogo de palavras tem início na própria acepção dos termos, conforme apresentado no sentido denotativo de cada um (importante $=$ interessante; interessante $=$ importante), caracterizando um fato semântico com palavras pertencentes ao mesmo campo lexical: a sinonímia.

Nesse contexto, ser importante é ser essencial, necessário; ser interessante é ser curioso, atraente, é prender a atenção e, para o produtor da Carta, a pesquisa espacial cativa e chama a atenção por ser curiosa, mas não essencial e meritória. Lyons (1982, p. 145) afirma que "os lexemas podem ser descritivamente sinônimos, mas ter significado expressivo e social diferente".

Isso significa que, apesar de se chegar a uma mesma acepção básica (importante $=$ interessante), a colocação dos dois não resulta em construções de valor idêntico, do ponto de vista comunicativo, porque "o importante é a identidade referencial, pois a sinonímia não é um problema puramente léxico, mas textual" (FÁVERO, 2006, p. 24). E diríamos, mais ainda, contextual.

Nas linhas 6 e 7, encontramos três adjetivos antepostos que marcam a interveniência de uma avaliação subjetiva do falante na qualificação efetuada:

Os melhores cérebros e uma astronômica cifra são aplicados em incertezas, enquanto nossa única certeza desmorona.

a) MELHORES cérebros
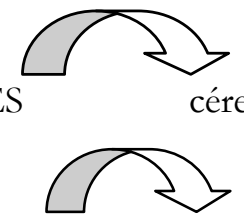

b) ASTRONÔMICA cifra

c) ÚNICA certeza 
Os exemplos citados corroboram a seguinte assertiva de Neves (2000, p.203): "Em geral, a anteposição do adjetivo cria ou reforça o caráter avaliativo - mais subjetivo - da qualificação". Em:

MELHORES cérebros

\section{Melhor}

[Do lat. meliore]

Adj.

1. Comp. de super. de bom; "mais

bom" (não é normal o uso de mais

bom) $[\ldots]$

ASTRONÔMICA cifra

ÚNICA certeza

\section{Astronômico}

[Do gr. astronomikós, pelo lat. astronomicu]. Adj.

1. Relativo à astronomia.

2. Fig. Muito elevado; altíssimo.

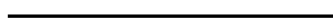

\section{$\underline{\text { Único }}$}

[Do lat. unicu].

Adj.

1. Que é só um.

2. De cuja espécie não existe outro.

3. Exclusivo, excepcional.

4. A que nada é comparável.

5. Superior a todos os demais. [...]

Temos três casos de adjetivação subjetiva de caráter intensificador. São adjetivos que já trazem, em sua significação, a noção intensificadora (melhores, astronômica, única), produzindo um efeito de maior envolvimento do produtor no ato da qualificação.

É relevante comentar os adjetivos pátrios europeia e japonesa (linha 2), chamados por Neves (2000) de adjetivos classificadores que, em função de adjunto adnominal, aparecem normalmente pospostos. Esses adjetivos pátrios revelam, também, um conhecimento de mundo do produtor que deve ser partilhado com o leitor para a compreensão da finalidade do 
enunciador ter citado Nasa (americana), agência espacial europeia e japonesa, ratificando um saber enciclopédico por parte do produtor: EUA, Europa e Japão investem MAIS em pesquisa espacial do que em preservação do planeta.

\section{Estratégias de Leitura}

Fávero (2006, p. 77) salienta que, para chegar à compreensão do texto como um todo coerente, é necessário que sejam trabalhadas não só as relações coesivas, mas, principalmente, as de conexão conceitual-cognitiva. "É preciso que o leitor/alocutário desenvolva habilidades que lhe permitam detectar as marcas que levarão às intenções do texto".

Desse modo, em consonância com Koch e Travaglia (1993), nosso conhecimento de mundo (enciclopédico) desempenha papel decisivo no estabelecimento da coerência.

\section{Conhecimento de mundo e coerência}

O título - Aquecimento Global - propicia ao leitor um avanço em relação ao conteúdo do texto, ativando todo saber acumulado que ele armazena a respeito do tema. Além disso, cada indivíduo armazena conhecimentos na memória a partir das experiências pessoais, o que impossibilita que as pessoas partilhem exatamente as mesmas informações, no entanto, favorece que produtor e receptor partilhem uma boa parcela de conhecimentos comuns.

$\mathrm{Na}$ Carta, as informações apresentadas fazem parte do contexto situacional em que o produtor (Wagner Lisso) sugere e solicita "prioridade na preservação do planeta". Também há informações que são de conhecimento geral, como os investimentos na pesquisa espacial - com larga exposição na mídia -, o efeito estufa e a ameaça do planeta. Outras informações remetem ao conhecimento partilhado entre produtor e leitor: EUA, Europa e Japão investem ' $x$ ' em pesquisa espacial e ' $y$ ' na preservação do planeta. O enunciado torna-se coerente quando o leitor, compartilhando das informações dadas, alcança a "nova" informação: Deve-se investir ' $x$ ' (e não ' $y$ ') na preservação do planeta para dirimir o efeito estufa, e, dessa forma, não deixar ruir "nossa única certeza". 
O conhecimento de mundo - ativado e, principalmente, partilhado entre os interlocutores - favorece o cálculo do sentido e, portanto, o estabelecimento da coerência textual.

\section{Conhecimento linguístico e seleção lexical}

Koch e Travaglia (2002, p. 54) chamam a atenção para a relação do linguístico com o conceitual-cognitivo (conhecimento de mundo) e com o pragmático, reforçando "ainda mais a importância das marcas lingüísticas como pistas para o cálculo do sentido e, portanto, da coerência do texto”.

Os referidos autores avaliam que traços linguísticos do enunciado, assim como a escolha do léxico, são importantes elementos para estabelecer a coesão pragmática. Assim, o material linguístico (o léxico) contido no texto representa a contextualização que essas formas linguísticas permitem. O conhecimento linguístico, em todos os níveis (fonético/fonológico, morfológico/lexical, sintático e semântico), é uma estratégia sociocognitiva que orienta o leitor na atividade de leitura e produção de sentido.

Conforme Koch e Elias (2006, p. 40), o conhecimento linguístico "abrange o conhecimento gramatical e lexical". Com esse tipo de conhecimento, o leitor pode compreender, entre outros recursos, "a seleção lexical adequada ao tema ou aos modelos cognitivos ativados" $(\mathrm{KOCH}$; ELIAS, 2006, p. 40). Um exemplo é o jogo de palavras importante X interessante, cuja mudança de posição interessante $\mathrm{X}$ importante expressa uma cuidadosa escolha lexical do produtor. Com base em suas acepções denotativas, o produtor da Carta - detentor desse conhecimento linguístico - efetuou uma alteração na posição dos adjetivos, avaliando, subjetivamente, a pesquisa espacial.

Para Koch (2000), a seleção lexical é de extrema importância para a construção dos sentidos.

O uso de fórmulas de gírias ou jargões profissionais, de determinado tipo de adjetivação, de termos diminutivos ou pejorativos fornece ao interlocutor pistas valiosas para a interpretação do texto e a captação dos propósitos com que é produzido. (KOCH, 2000, p. 44). 
É sabido que a seleção lexical traduz as reais intenções do enunciador, revelando suas opiniões e crenças acerca do tema tratado. A escolha lexical, nessa Carta, estende-se também a alguns substantivos e a um verbo (podendo até formar o frame meio ambiente).

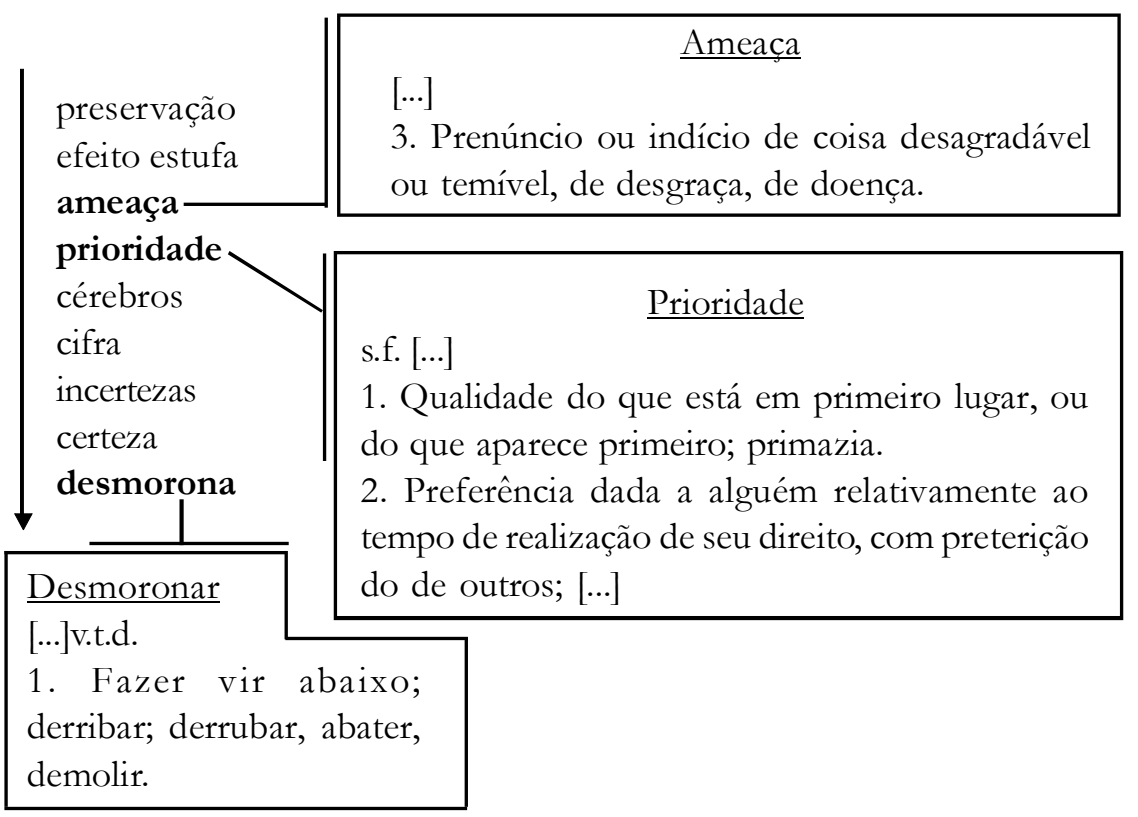

Os substantivos ameaça e prioridade e o verbo desmorona exemplificam a importância da seleção lexical na construção de sentidos de um texto. Aliás, as palavras elencadas resumem o significado global do texto:

* A preservação do planeta e o efeito estufa, que é uma ameaça, são prioridades atuais. Cérebros e cifra não devem ser usados com incertezas, mas com a única certeza que temos, antes que o planeta desmorone.

O jogo de palavras incertezas X certeza (antonímia) colabora, por certo, para a efetivação dos sentidos da Carta. 


\section{Outros Recursos Argumentativos}

\section{a) Antonímia}

Além da possível sinonímia entre os termos interessante e importante, já comentada, outro mecanismo de coesão lexical responsável pela reiteração de referentes textuais é a antonímia.

Os melhores cérebros e uma astronômica cifra são aplicados em incertezas, enquanto nossa única certeza desmorona.

\begin{tabular}{|c|c|}
\hline $\begin{array}{l}\quad \underline{\text { Incerteza }} \\
\text { [De in- + certeza.] } \\
\text { s.f. } \\
\text { 1. Falta de certeza; hesitação; } \\
\text { indecisão; perplexidade; dúvida. }\end{array}$ & $\begin{array}{l}\text { Certeza } \\
{[\text { De certo }+ \text { eza }]} \\
\text { s.f. } \\
{[\ldots . .]} \\
\text { 2.Conhecimento exato. } \\
\text { 3.Persuasão íntima, convicção. [...] } \\
\text { 6.Afirmação categórica; intimativa. }\end{array}$ \\
\hline
\end{tabular}

Lyons (1982), ao discutir a questão da antonímia, trata da incompatibilidade de sentido, dizendo que

o ponto teoricamente importante da antonímia é que a incompatibilidade, e mais especialmente a oposição, entre os sentidos, é uma das relações estruturais básicas nos vocabulários de todas as línguas. (LYONS, 1982, p. 149).

Assim: 


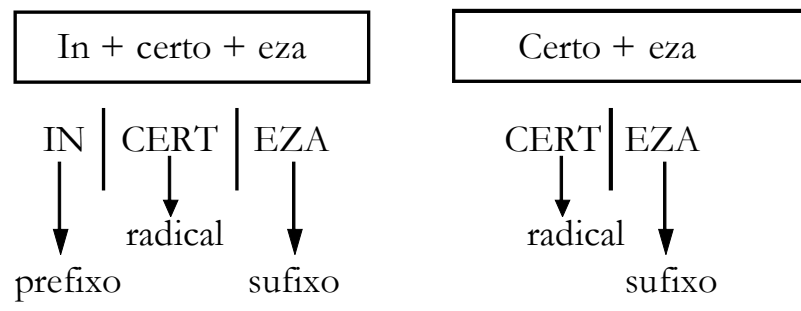

A oposição entre essas palavras tem início na própria estrutura mórfica dos termos (nível morfológico), sendo ampliada para o nível semântico, construção dos sentidos pretendidos pelo produtor:

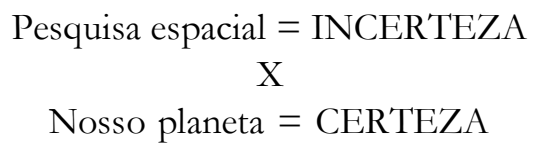

O jogo antonímico é um forte recurso persuasivo para ganhar a adesão do leitor, principalmente, considerando o efeito do prefixo IN- = "negação", "privação", portanto, INCERTEZAS = privação de certeza. Esse jogo estende-se, e ganha força, a outro recurso utilizado na Carta: a negação.

\section{b) Negação}

Nas linhas 3 e 4, o advérbio de negação NÃO aparece três vezes:

Se os gastos de um ano da Nasa, da agência espacial européia, da japonesa e de outras fossem aplicados na preservação do planeta, o efeito estufa com certeza não seria a ameaça que é hoje. $\underline{\text { Não que a }}$ pesquisa espacial não seja importante e interessante, na verdade muito mais interessante do que importante, mas é uma questão de prioridade.

Segundo Neves (2000, p.238), os advérbios de negação "operam sobre o valor de verdade da oração"; são advérbios que "não afetam o significado do elemento sobre o qual incidem". A negação é um recurso argumentativo, é um processo formador de sentido, "agindo como instrumento de interação dotado de intencionalidade” (NEVES, 2000, p. 285). 
A negação atua no nível sintático-semântico (no interior do enunciado) e, também, no nível pragmático:

a) ... NÃO seria a ameaça que é hoje.

b) ... NÃO que a pesquisa espacial...

c) ... NÃO seja importante e interessante.

Ademais, a reiteração, a repetição do advérbio NÃO (mesmo item lexical) constitui-se em um eficiente recurso de coesão referencial, com a finalidade de direcionar o leitor aos propósitos pretendidos pelo produtor.

\section{c) Intensificadores}

Conforme exposto, o advérbio MUITO intensifica o comparativo de superioridade mais...do que:

Não que a pesquisa espacial não seja importante e interessante, na verdade muito mais interessante do que importante, mas é uma questão de prioridade.

Além disso, quando anteposto a outro advérbio intensificador (mais), MUITO reitera o valor atribuído ao adjetivo interessante e minimiza o adjetivo importante.

Os adjetivos intensificadores (melhores, astronômica, única), já comentados anteriormente, intensificam e indicam qualificações mais subjetivamente atribuídas aos respectivos substantivos: cérebros, cifra, certeza.

O processo de intensificação é um recurso persuasivo que enfatiza a carga significativa de uma palavra, de uma expressão ou de um texto, evidenciando seu caráter afetivo-argumentativo.

\section{Considerações Finais}

A análise dos aspectos textuais, linguísticos e cognitivos utilizados pelo produtor da Carta torna possível estabelecer uma relação direta da leitura com os processos argumentativos, uma vez que estes fazem parte da gama de aspectos que envolvem as marcas textuais de subjetividade; são recursos semânticos, morfossintáticos e exercem papel fundamental na articulação do texto. Podemos observar, no processo de construção da Carta, que os recursos linguístico-argumentativos e cognitivos exercem um poder de 
persuasão intenso no leitor. O jogo de palavras e de ideias, mesclado aos processos semânticos e pragmáticos presentes no texto, estabelecem, de fato, uma interação entre produtor-texto-leitor. Assim, a Carta cumpre seu principal papel: a interação social por meio da linguagem.

A Carta do Leitor apresenta marcas do autor no texto, revela as intencionalidades do produtor, traz o posicionamento ideológico do enunciador, possibilitando que o leitor preencha os vazios textuais e, consequentemente, "ajude o texto a funcionar" (ECO, 1983, p.57).

Os produtores de cartas do leitor tentam aproximar-se de seus leitores, envolvendo-os com recursos linguístico-cognitivos por meio de uma linguagem precisa e direta. Em alguns momentos, introduzem elementos, aparentemente destoantes, como marcas de oralidade, perguntas retóricas, expressões coloquiais, eufemismos que, na verdade, trazem vivacidade ao texto e convidam o leitor a se aproximar um pouco mais.

Comprovamos, então, que o produtor da carta elabora, passo a passo, suas escolhas linguísticas, visando a interagir de modo mais eficaz com o leitor, que desempenha um papel social e discursivo muito significativo na construção textual. Salientamos, também, a riqueza do material da mídia impressa enquanto objeto de leitura na escola e como um caminho possível para a formação de leitores.

\section{Referências}

BASÍLIO, M. Teoria lexical. 2. ed. São Paulo: Ática, 1989.

DUCROT, O. Provar e dizer: linguagem e lógica. Tradução Maria Aparecida Barbosa, Maria de Fátima Gonçalves Moreira e Cidmar Teodoro Pais. São Paulo: Global Universitária, 1981.

DUCROT, O. O dizere e o dito. Revisão da tradução Eduardo Guimarães. Campinas: Pontes, 1987.

ECO, U. Leitura do texto literário. Lector in fábula. Lisboa: Presença, 1983. FÁVERO, L. Coesão e coerência textuais. 11. ed. São Paulo: Ática, 2006. 
FIORIN, J. L. As figuras de pensamento: estratégia do enunciador para persuadir o enunciatário. Alfa, São Paulo, v. 32, 1988.

FIORIN, J. L. A lógica da neutralidade: um caso de aspectualização do ator. Anais de Seminários do GEL - Estudos Lingüísticos XVIII. Lorena: GEL, 1989.

GUIMARÃES, E. Texto e argumentação: um estudo de conjunções do Português. Campinas: Pontes, 1987.

HOUAISS, A. Dicionário Houaiss da língua portuguesa. São Paulo: Objetiva, 2001.

KERBRAT-ORECCHIONI, C. L'Enonciation: de la subjectivité dans le langage. Paris: Armand Colin, 1980.

KLEIMAN, A. Texto e leitor: aspectos cognitivos da leitura. Campinas: Pontes, 1989.

KOCH, I. V. A coesão textual. São Paulo: Contexto, 1989.

KOCH, I. V. O texto e a construção do sentido. São Paulo: Contexto, 2000.

KOCH, I. V. Argumentação e linguagem. 7. ed. São Paulo: Cortez, 2002a.

KOCH, I. V. Desvendando os segredos do texto. São Paulo: Cortez, 2002b.

KOCH, I. V.; ELIAS, V. Ler e compreender: os sentidos do texto. São Paulo: Contexto, 2006.

KOCH, I. V.; TRAVAGLIA, Luiz C. A coerência textual. 5. ed. São Paulo: Contexto, 1993.

KOCH, I. V.; TRAVAGLIA, Luiz C. Texto e coerência. 8. ed. São Paulo: Cortez, 2002.

LISSO, W. Aquecimento global. In: Veja, São Paulo, a. 40, ed. 1990, n. 1, 10 jan. 2007. p. 20. (Seção Cartas).

LYONS, J. Linguagem e lingüistica: uma introdução. Tradução brasileira Marilda Winkler Averbug e Clarisse S. de Souza. Rio de Janeiro: Zahar, 1982. 
MARCUSCHI, L. A. Gêneros textuais: definição e funcionalidade. In: DIONÍSIO, A. P.; MACHADO, A. R.; BEZERRA, M. A. (Orgs). Gêneros textuais e ensino. Rio de Janeiro: Lucerna, 2002. p. 19-36.

MONTEIRO, J. L. A estilistica. São Paulo: Ática, 1991.

NEVES, M. H. de M. Gramática de usos do português. São Paulo: Editora UNESP, 2000. 